\title{
Anticancer Effect of Solid-Lipid Nanoparticles Containing Mentha longifolia and Mentha pulegium Essential Oils: In Vitro Study on Human Melanoma and Breast Cancer Cell Lines
}

\author{
Hamid Reza Kelidari ${ }^{1(D)}$, Hiva Alipanah ${ }^{2}$ (D) , Ghazaal Roozitalab ${ }^{3}$ (D), Maryam Ebrahimi ${ }^{4}$, Mahmoud \\ Osanloo $5, *$ (D)
}

1 Pharmaceutical Sciences Research Center, Mazandaran University of Medical Sciences, Sari, Iran; hamidreza.kelidari@yahoo.com (HR.K);

2 Department of Physiology, School of Medicine, Fasa University of Medical Sciences, Fasa, Iran; hamidreza.kelidari@yahoo.com (H.A);

3 Noncommunicable Diseases Research Center, Fasa University of Medical Sciences, Fasa, Iran; ghazaal.rzt@gmail.com (G.R);

4 Department of Medical Nanotechnology, School of Advanced Technologies in Medicine, Fasa University of Medical Sciences, Fasa, Iran; maryam.ebrahimi888@gmail.com (M.E);

5 Department of Medical Nanotechnology, School of Advanced Technologies in Medicine, Fasa University of Medical Sciences, Fasa, Iran; m.osanloo@fums.ac.ir (M.O);

* Corresponding authors: m.osanloo@fums.ac.ir, osanloo_mahmood@yahoo.com (M.O.);

Scopus Author ID 57192379172

Received: 15.04.2021; Revised: 20.05.2021; Accepted: 23.05.2021; Published: 18.06.2021

\begin{abstract}
Breast cancer and melanoma are common cancers with several treatments such as surgery, radiotherapy, chemotherapy, and their side effects. Therefore, new drugs using plant-derived substances (especially essential oils) have received more attention in recent years; however, they are generally less effective than synthetic drugs. Therefore, the preparation of essential oil-based nanoformulations is considered a promising approach to improving their efficiency. In this study, ingredients of Mentha longifolia and Mentha pulegium essential oils were first identified by GC-MS analysis. Their anticancer effects were then evaluated against one melanoma cell line (A-375) and two breast cancer cell lines (MDA-MB-468 and MCF-7). The cytotoxic effect of the essential oil on all cell lines at even the highest concentration, $1200 \mu \mathrm{g} / \mathrm{mL}$, was not proper (viability > 55\%). After that, solid lipid nanoparticles containing each essential oil with particle sizes of $107 \pm 9$ (PDI 0.274) and $191 \pm 8$ (PDI 0.174) nm and zeta potential -7.10 and $-4.81 \mathrm{mV}$ were prepared. Interestingly, both prepared nanoformulations reduced the viability of all three cell lines to around $10 \%$ at half the mentioned concentration, $600 \mu \mathrm{g} / \mathrm{mL}$. Thus, the prepared nanoformulations could be introduced as proper candidates for investigation in-vivo research and supplementary medicine.
\end{abstract}

Keywords: anticancer effect; A-375; MCF-7; MDA-MB-468.

(C) 2021 by the authors. This article is an open-access article distributed under the terms and conditions of the Creative Commons Attribution (CC BY) license (https://creativecommons.org/licenses/by/4.0/).

\section{Introduction}

Uncontrolled or abnormal growth and proliferation of cells (in any organ of the body) is called cancer; melanoma and breast cancer are common cancers worldwide [1,2]. The prevalence of melanoma is increasing worldwide; it is the cause of $75 \%$ of skin cancer-related deaths $[3,4]$. A-375 cells are among the most widely used melanoma cell lines in research; it is more aggressive with high metastatic potential and low responsiveness to chemotherapy $[5,6]$. https://biointerfaceresearch.com/ 
Breast cancer is the first common cancer in females, impacting over 1.5 million women annually $[7,8]$. Amongst breast cancer cell lines, MCF-7 is the most commonly studied due to hormone sensitivity and estrogen receptor expression $[9,10]$. MDA-MB-468, without estrogen and progesterone receptors and HER2 non-expression (triple-negative), is another commonly studied cell line [11,12].

Plant-derived substances (especially EOs) have recently received more attention due to occurring resistance in cancers against chemotropic drugs. Essential oils (EOs) are naturally secreted oil as secondary metabolites in aromatic plants [13]. They have been widely used in the cosmetic, food, and pharmaceutical industries due to their bioactive compounds $[14,15]$. Mentha is a genus of the Lamiaceae family, which contains approximately 220 genera and 3300 species [16]. Mentha longifolia and Mentha pulegium are two important medicinal plants from this family, which have achieved a special place in the pharmaceutical industry $[17,18]$. M. longifolia, commonly known as "wild mint," could be useful for the treatment of bronchitis, headache, cough, nausea, asthma, liver diseases, digestive disorders, stomach, abdominal disorders, etc. $[19,20]$. M. pulegium, commonly known as "pennyroyal" could be useful for the treatment of colds, sinusitis, cholera, food poisoning, abdominal cramps, smallpox, bronchitis and tuberculosis [21,22]. Other biological actives such as antispasmodic, anticancerous, antimicrobial, antioxidative, anticandidal, insect repellent, anticholinergic, antidiabetic, and neuroprotective effects have also been reported for their EOs [23,24].

Nowadays, formulating EOs as nanoformulations such as nanoemulsions and polymeric or lipidic nanoparticles is a promising approach to improving their effectiveness and adjusting their concentration to achieve proper efficiency [25,26]. Lipid nanoparticles, also known as solid lipid nanoparticles (SLNs) with lipophilic ingredients, are proper carriers for loading EOs; they have unique features such as small size, large surface area, high drug loading, and low toxicity $[27,28]$.

In this study, the cytotoxic effect of EOs of M. longifolia (MLEO) and M. pulegium (MPEO) was first investigated on A375, MCF7, and MDA-MB-468 cancer cell lines. By formulating them as solid lipid nanoparticles, we then tried to improve their efficiency.

\section{Materials and Methods}

\subsection{Materials.}

MCF-7 (ATCC HTB-22) and MDA-MB-468 (ATCC HTB-22) breast cancer cell lines, as well as melanoma cell line A-375 (ATCC CRL-1619), were provided by the Pasteur Institute of Iran. Sigma-Aldrich (USA) provided tetrazolium salt, 3-(4,5-dimethyl-thiazol-2-yl)-2,5diphenyltetrazo-lium bromide (MTT) and phosphate-buffered saline (PBS) tablets. Shellmax (China) supplied penicillin-streptomycin, trypsin, Dimethyl Sulfoxide (DMSO), and Dulbecco's Modified Eagle's Media (DMEM) cell culture medium. Gibco (USA) provided fetal bovine serum (FBS). Merck Co. (Germany) supplied the stearic acid, Tween 80, and Span 60. A Milli-Q water system (Milli-pore, Direct-Q) was used to purify deionized water.

\subsection{GC-MS analysis.}

For identifying constituents of MLEO and MPEO, GC-MS analysis was used as described in our previous study [29]. 


\subsection{Preparation of SLN containing EOs.}

The high-pressure homogenizer method was used to prepare MLEO and MPEO containing SLNs (ML-SLNs and MP-SLNs), as described in our previous research (30). Briefly, MLEO and MPEO (1\% v/v) was first dissolved in the melted solid lipid (stearic acid $4 \% \mathrm{v} / \mathrm{v}, 85^{\circ} \mathrm{C}$ ) and lipophilic surfactant (Span 60, 2\% v/v). After that, the mixture was distributed in a heated aqueous surfactant solution, tween $804 \% \mathrm{v} / \mathrm{v}$; subjected to high-shear homogenizer (D-91126 Schwabach, Heidolph, Germany) for 1 minute at $8000 \mathrm{rpm}$. The obtained pre-emulsion was then homogenized at high pressure (3 cycles, 500 bar) using an APV Micron Lab 40 (APV Systems, Unna, Germany) thermostated at $90^{\circ} \mathrm{C}$.

\subsection{Characterization of SLNs.}

The particle size, polydispersity index, and zeta-potential of the nanoparticles were determined using Malvern zetasizer (Malvern Instruments, UK). The sample was calibrated at $25^{\circ} \mathrm{C}$ with an angle detection of 90 in this process. The samples' concentration for analysis on the Zeta sizer was 20-400 kilo counts per second (KCPS), and 100000 counts per second were the intensity of diffraction.

\subsection{MTT assay.}

MTT assay was used to investigate the anticancer functions of MLEO and MPEO (as bulk samples) as well as ML-SLNs and MP-SLNs (as nanoformulations). MLEO and MPEO were dissolved $(4800 \mu \mathrm{g} / \mathrm{mL})$ in PBS solution containing $0.5 \%$ DMSO; required concentrations were also prepared using the same solvent.

The A-375, MCF-7, and MDA-MB-468 cell lines were cultured at $75 \mathrm{~cm} 2$ culture flasks $\left(37{ }^{\circ} \mathrm{C}, 5 \% \mathrm{CO} 2\right)$ in DMEM perfect medium containing FBS (10\%) and Penicillinstreptomycin (1\%). Separated cells from a flask, using trypsin, were seeded in 96-well plates and incubated for 24 hours. The culture media was then discarded, and each well was filled with $75 \mu \mathrm{L}$ of full fresh medium. Concentrations were set at $1200,600,300,150$, and $75 \mu \mathrm{g} / \mathrm{mL}$ after applying the samples' desired amount. After $24 \mathrm{~h}$ of incubation, the plate contents were discarded, and the wells were washed with PBS to clear the milky color of the nanoformulations. Every well was then filled with $100 \mu \mathrm{L}$ MTT solution $(0.5 \mathrm{mg} / \mathrm{mL})$, and plates were incubated for 4 hours. Finally, $100 \mu \mathrm{L} /$ well of DMSO was applied to each well to dissolve the formed formazan crystals. Using an ELISA Plate Reader, the absorbance of each well was measured at $570 \mathrm{~nm}$. Dividing the mean absorbance of each sample's concentration by the mean absorbance of the control group, cell viability was calculated. The test was performed in triplicate; six wells were considered the control in each plate, filled with PBS solution containing 0.5\% DMSO $(25 \mu \mathrm{L})$ and DMEM $(75 \mu \mathrm{L})$.

\section{Results and Discussion}

\subsection{Ingredients of CSEO.}

Constituents of MLEO and MPEO were identified using GC-MS analysis comprising more than $1 \%$ (see Table 1). All ingredients have been arranged by retention time (RT) from smaller to larger. Five major components of MLEO are pulegone (\% 47.6), 1,8-cineole(\%12.6), piperitenone (\%5.6), menthofuran (\%4.6) and arvone (\%4.1). Five major components of 
MPEO are pulegone (\%69.0), trans-cyclohexanone, 5-methyl-2-(1-methylethyl) (\%9.4), limonene (\%4.0), 8-hydroxy-p-menthan-3-one (\%3.7) and Iso-pulegone (\%3.4).

Table 1. Identified ingredients (>1\%) in the MLEO and MPEO using GC-MS analysis.

\begin{tabular}{|c|c|c|c|c|c|c|c|}
\hline \multirow[t]{2}{*}{ No. } & \multirow[t]{2}{*}{${ }^{\text {a }} \mathbf{R T}$} & \multirow[t]{2}{*}{ Compound } & \multirow[t]{2}{*}{${ }^{\mathbf{b}} \mathbf{R I}$} & \multicolumn{2}{|c|}{ MLEO } & \multicolumn{2}{|c|}{ MPEO } \\
\hline & & & & Area & $\%$ & Area & $\%$ \\
\hline 1 & 9.4 & $\alpha$-pinene & 622 & 29138914 & 1.8 & -- & -- \\
\hline 2 & 11.1 & sabinene & 689 & 19211346 & 1.2 & -- & -- \\
\hline 3 & 11.2 & $\beta$-pinene & 693 & 36089576 & 2.3 & -- & -- \\
\hline 4 & 12.2 & 3-octanol & 721 & -- & -- & 31660011 & 1.3 \\
\hline 5 & 13.6 & limonene & 756 & 61759470 & 3.9 & 96878221 & 4.0 \\
\hline 6 & 13.7 & 1,8-cineole & 759 & 197657002 & 12.6 & -- & -- \\
\hline 7 & 19.2 & 5,7-octadienoic acid, methyl ester & 879 & 35260468 & 2.2 & -- & -- \\
\hline 8 & 19.5 & $\begin{array}{l}\text { trans-cyclohexanone, 5-methyl-2-(1- } \\
\text { methylethyl) }\end{array}$ & 884 & -- & -- & 223515392 & 9.4 \\
\hline 9 & 19.9 & menthofuran & 892 & 71977135 & 4.6 & -- & -- \\
\hline 10 & 19.9 & $\begin{array}{ll}\text { cis-cyclohexanone, } & \text { 5-methyl-2-(1- } \\
\text { methylethyl) } & \end{array}$ & 893 & -- & -- & 33275891 & 1.3 \\
\hline 11 & 20.1 & borneol & 896 & 20202046 & 1.2 & -- & -- \\
\hline 12 & 20.5 & Iso-pulegone & 904 & 26990916 & 1.7 & 80850780 & 3.4 \\
\hline 13 & 21.5 & Iso-dihydrocarvone & 923 & 18371508 & 1.1 & -- & -- \\
\hline 14 & 23.7 & pulegone & 963 & 746264316 & 47.6 & 1642627212 & 69.0 \\
\hline 15 & 23.8 & carvone & 965 & 64391028 & 4.1 & -- & -- \\
\hline 16 & 24.2 & 8-hydroxy-p-menthan-3-one & 972 & -- & -- & 88487891 & 3.7 \\
\hline 17 & 24.8 & 8-hydroxy-p-menthan-3-one & 984 & -- & -- & 31372778 & 1.3 \\
\hline 18 & 28.0 & piperitenone & 1045 & 89158439 & 5.6 & 30048157 & 1.2 \\
\hline 19 & 29.1 & piperitenone oxide & 1066 & 27012819 & 1.7 & -- & -- \\
\hline 20 & 31.2 & trans-caryophyllene & 1106 & 19455003 & 1.2 & -- & -- \\
\hline
\end{tabular}

\subsection{Characteristics of the prepared nanoformulation (ML-SLNs and MP-SLNS).}

DLS analysis and potential zeta profile of ML-SLNs and MP-SLNs are depicted in Figures 1 and 2 . Their particle sizes were $107 \pm 9$ and $191 \pm 8 \mathrm{~nm}$, polydispersity indexes (PDI) were 0.274 and 0.174 , and zeta potentials were -7.10 and $-4.81 \mathrm{mV}$. In phospholipid vesicles, a PDI $<0.3$ is considered a homogenous formulation; thus, both prepared nanoformulations had satisfying properties [30,31].

The current research is the first study to deal with MLEO or MPEO (ML-SLNs and MP-SLNs) preparation as the anticancer agent to the authors' best knowledge. One research on the preparation of MP-SLNs with a particle size of $202 \mathrm{~nm}$, PDI 0.76, and zeta potential -26.7 as an antibacterial agent against dental caries was reported previously [32].

From the literature, some reports on the preparation of SLNs containing other EOs have also been found. For instance, in our previous report, Zataria multiflora essential oil was loaded in SLNs with a particle size of $134 \pm 7 \mathrm{~nm}$, PDI 0.24, and zeta potential -9.82. The prepared nanoformulation's repellent effect against the main malaria vector, Anopheles stephensi, was 93 min compared to 29 min for no-formulated EO [33]. By another group, Z. multiflora essential oil was loaded in SLNs with a particle size of around $255 \mathrm{~nm}$, PDI 0.369, and zeta potential $-37.8 \mathrm{mV}$; its antifungal properties were investigated [34]. There have also been reports of the preparation of nanoparticles containing other EOs. For example, Yuxingcao EO was loaded in SLNs with a particle size of $171 \mathrm{~nm}$ and zeta potential of $17.1 \mathrm{mV}$ [35]. Essential oils of frankincense and myrrh (FMO) were loaded in SLNs with a mean size of $113.3 \pm 3.6$ $\mathrm{nm}$ and zeta potential $-16.8 \pm 0.4 \mathrm{mV}$ [36]. 

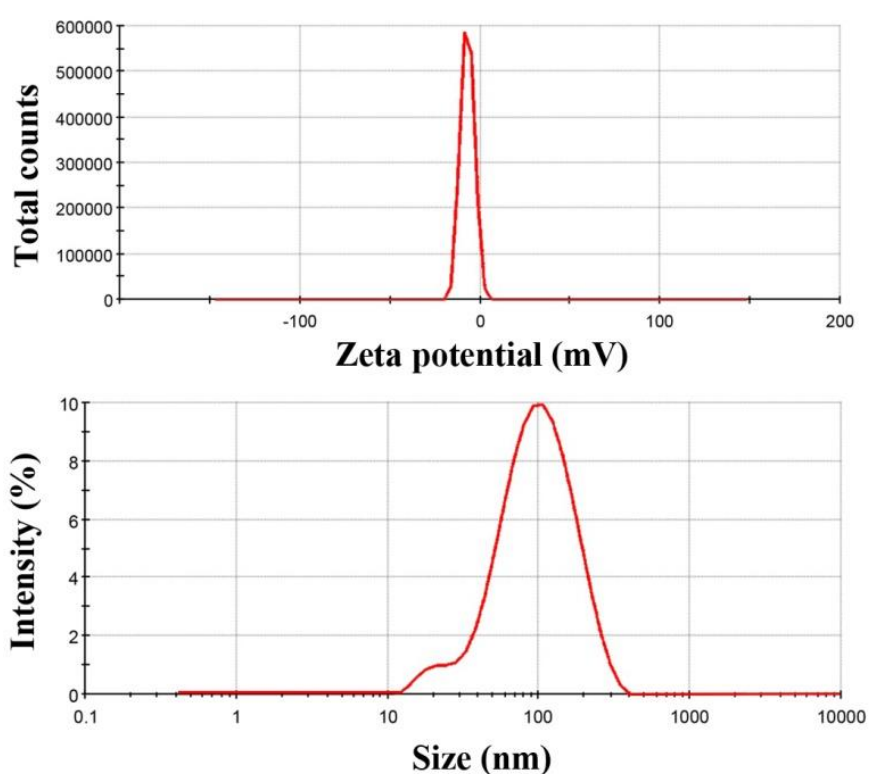

Figure 1. Zeta potential, -7.10 $\mathrm{mV}$ (top), and DLS analysis (down) of solid-lipid nanoparticles containing $M$. longifolia EO (ML-SLNs) with a particle size of $107 \pm 9 \mathrm{~nm}$ and PDI 0.274.
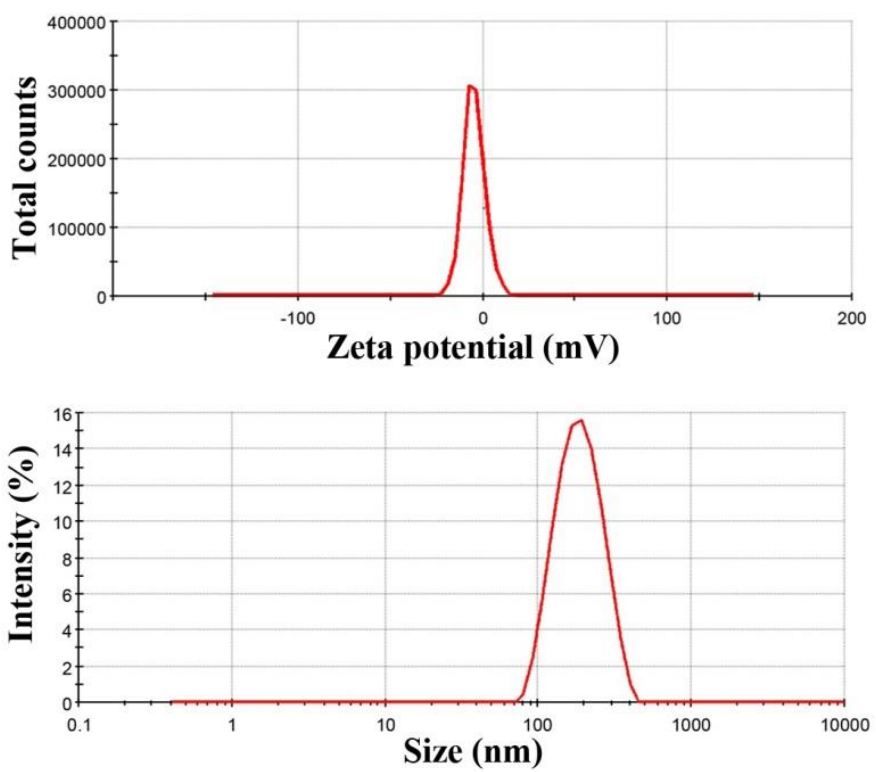

Figure 2. Zeta potential, $-4.81 \mathrm{mV}$ (top), and DLS analysis (down) of solid-lipid nanoparticles containing $M$. pulegium EO (MP-SLNs) with a particle size of $191 \pm 8 \mathrm{~nm}$ and PDI 0.174

\subsection{Comparison of cytotoxic effect of the EOs and their nanoformulated forms.}

Anticancer effects of MLEO and MPEO and their nanoformulated forms, ML-SLNs and MP-SLNs, against A-375 cells are depicted in Figure 3. MP-SLNs showed significantly more potent than MPEO at all examined concentrations ( $p<0.001)$, and ML-SLNs at four concentrations, including $150,300,600$, and $1200 \mu \mathrm{g} / \mathrm{mL}$ was significantly more potent than MLEO. The cell's viability at the highest concentration $(1200 \mu \mathrm{g} / \mathrm{mL})$ of MLEO and MPEO was decreased to 89 and $73 \%$. Our findings from the MTT assay interestingly provide that the highest anticancer activity was observed after $24 \mathrm{~h}$ treatment of the A-375 cells with ML-SLNs and MP-SLNs in 600 and $1200 \mu \mathrm{g} / \mathrm{mL}$ concentrations; the viability of A-375 was reduced to < $5 \%$. 


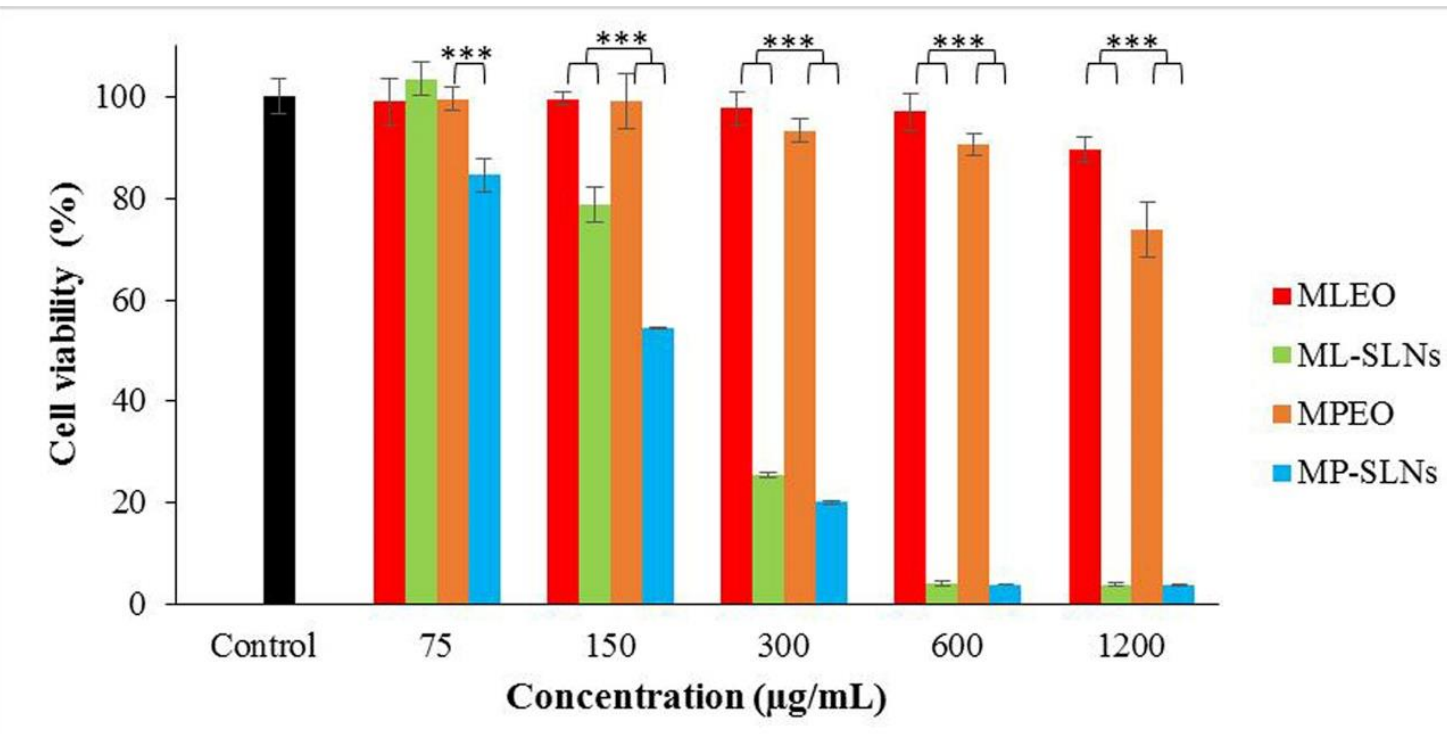

Figure 3. Comparison of cytotoxic effect of EOs of M. longifolia and M. pulegium (MLEO and MPEO) and their nanoformulated forms (ML-SLNs and MP-SLNs) on A-375. Data are presented as mean \pm standard deviations $(\mathrm{n}=3)$. ***: $\mathrm{p}<0.001$.

Anticancer effects of MLEO, MPEO, ML-SLNs, and MP-SLNs, against MCF-7 cells are illustrated in Figure 4. ML-SLNs at all examined concentration was more potent $(p<0.001)$ than its no-formulated form MLEO, and cytotoxic effect of MP-SLNs was more potent ( $\mathrm{p}<$ 0.001 ) than MLEO at four concentration including 150, 300, 600, and $1200 \mu \mathrm{g} / \mathrm{mL}$. Cell viability after treatment with MLEO and MPEO $1200 \mu \mathrm{g} / \mathrm{mL}$ were decreased to 83 and $74 \%$. Notably, the present results show that MCF-7 cells (for $24 \mathrm{~h}$ ) treatment with ML-SLNs and MP-SLNs with 600 and $1200 \mu \mathrm{g} / \mathrm{mL}$ reduced cell viability to $<7 \%$. These results suggested that ML-SLNs and MP-SLNs exerted a more significant inhibitory effect on the breast cancer cell line.

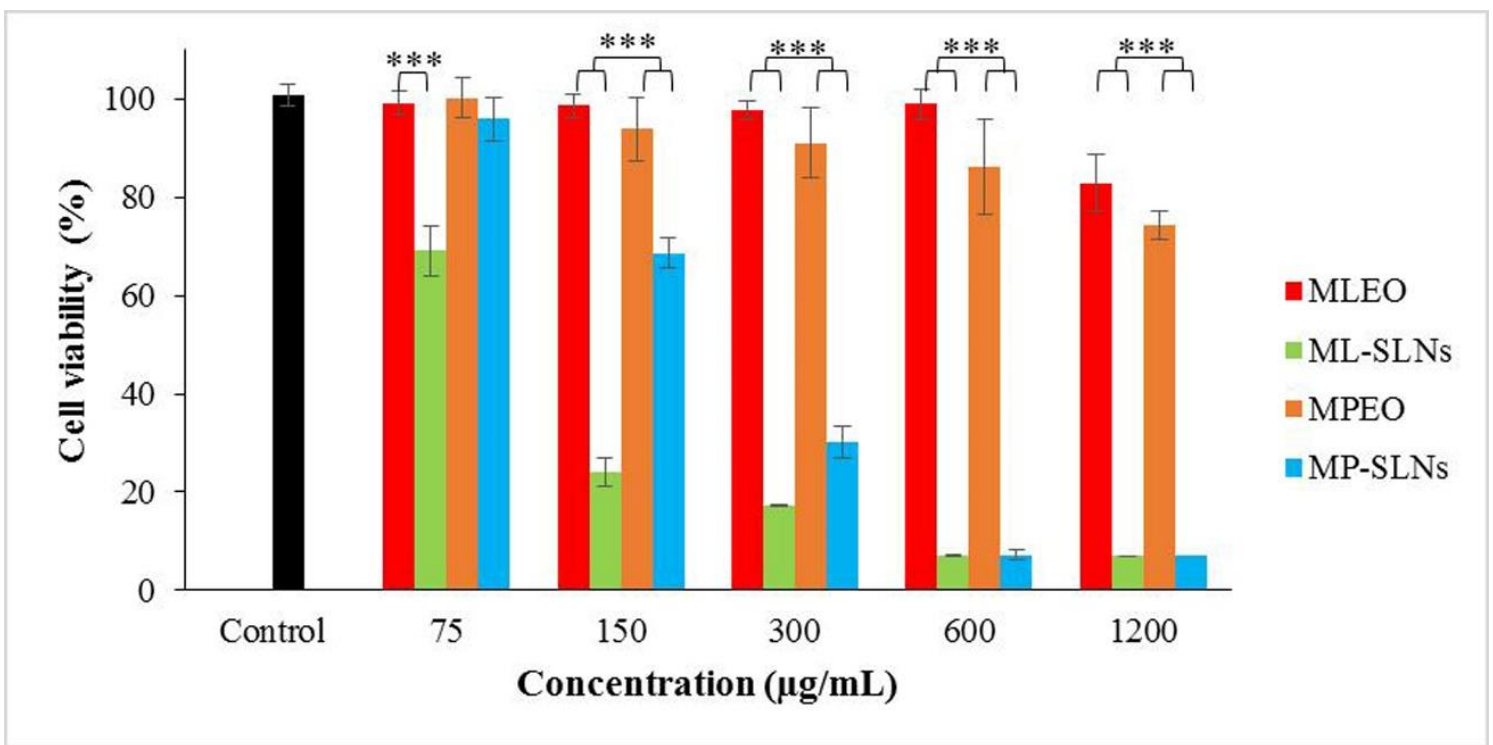

Figure 4. Comparison of cytotoxic effect of EOs of M. longifolia and M. pulegium (MLEO and MPEO) and their nanoformulated forms (ML-SLNs and MP-SLNs) on MCF-7. Data are presented as mean \pm standard deviations $(\mathrm{n}=3)$. ***: $\mathrm{p}<0.001$.

Anticancer effects of MLEO and ML-SLNs, as well as MPEO and MP-SLNs on MDAMB-468, are compared in Figure 5. Both nanoformulations (ML-SLNs and MP-SLNs) at all examined concentrations were more potent $(\mathrm{p}<0.001)$ than their no-formulated forms (MLEO 
and MPEO). The cells' viability at $1200 \mu \mathrm{g} / \mathrm{mL}$ of MLEO and MPEO (highest concentration) was decreased to 57 and $88 \%$. Interestingly, the results showed that ML-SLNs and MP-SLNs therapies at three concentrations of 300,600 , and $1200 \mu \mathrm{g} / \mathrm{mL}$ had reduced the cells' viability to $<15 \%$.

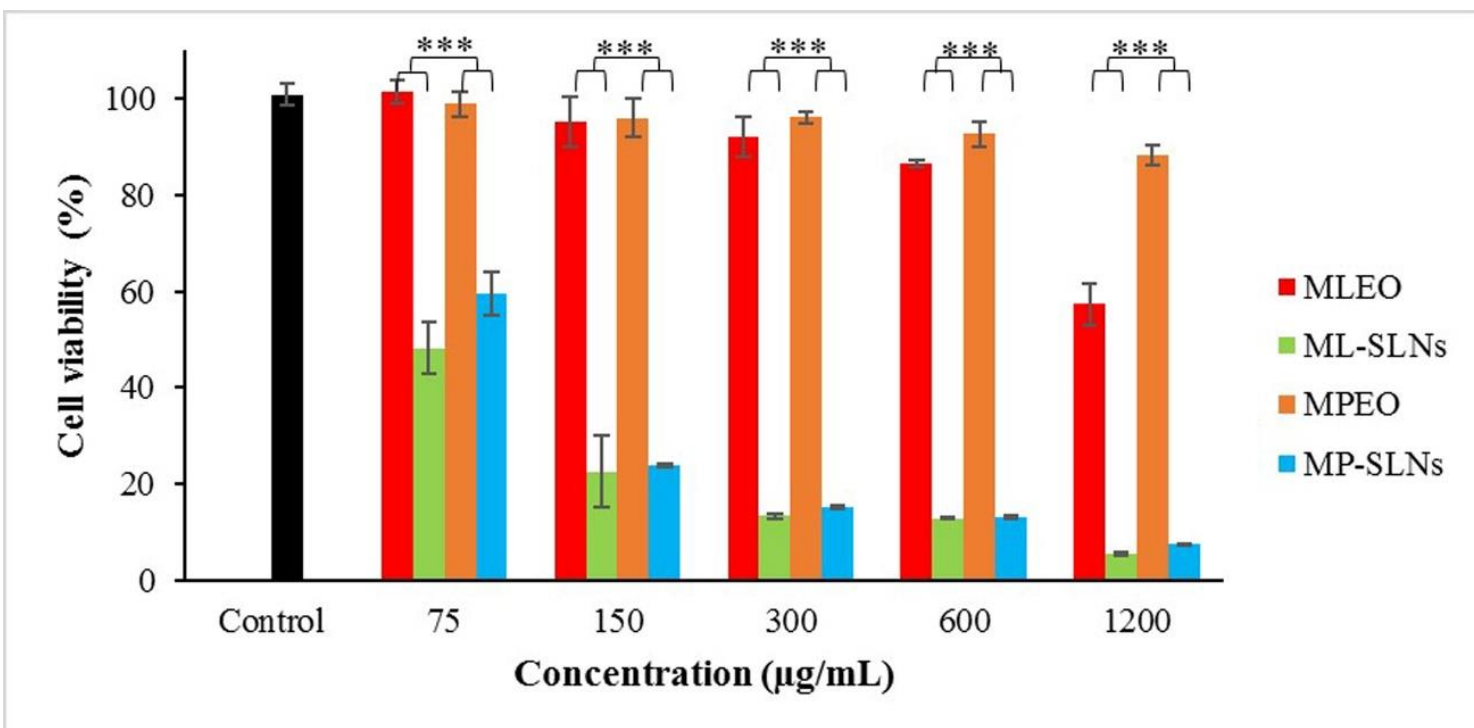

Figure 5. Comparison cytotoxic effect of EOs of M. longifolia and M. pulegium (MLEO and MPEO) and their nanoformulated forms (ML-SLNs and MP-SLNs) on MDA-MB-468. Data are presented as mean \pm standard deviations $(\mathrm{n}=3)$. ***: $\mathrm{p}<0.001$.

The use of nanocarriers (niosome, nanoemulsions, SLNs, nanofibers, and polymeric nanoparticles) to improve pharmacokinetics and the bioavailability of therapeutic agents has recently received more attention [37,38]. For example, in vitro cytotoxicity assay of HepG2, MCF-7, and A549 cell lines showed that D-limonene-loaded niosome had a noticeable anticancer effect compared to D-limonene and empty niosome; it reduced viabilities of the cells to $\sim 40 \%$ at a concentration of $20 \mu \mathrm{M}$ [37]. Moreover, by preparing EO-based nanoformulations, the droplets' dispersion is uniform in the aqueous medium. Therefore, it leads to more and better interactions with the cell; improved nanoformulation efficiency compared to the non-formulated state is more likely [39,40]. This improvement also results from decreasing EOs droplet size and better penetration into the cells [41,42]. In our previous study, the anticancer effect of nanoemulsion of Mentha piperita EO with a mean droplet size of $136 \pm 2 \mathrm{~nm}$ (PDI 0.3) was significantly better $(p<0.001)$ than that of non-formulated EO; the obtained effect with an exposure time of $24 \mathrm{~h}$ was significantly better than non-formulated EO within 72-h exposure time [43]. From the literature, SLNs containing limonene reduced growth percentages in cancer cells with a low toxic effect on the non-tumoral cell line; however, no comparison was performed with non-formulated limonene [44]. In another study, the antioxidant activity of limonene emulsion with a particle size of $339.5 \mathrm{~nm}$ showed more potent than bulk limonene; concluded that encapsulation could solve its low solubility in water and enhance its bioactivity [45].

\section{Conclusions}

Ingredients of $M$. longifolia and $M$. pulegium were first identified using GC-MS analysis; pulegone was the major constituent of both. They showed no proper cytotoxic effect on A-375 (melanoma cell line), MDA-MB-468, and MCF-7 (breast cancer cell lines). However, solid-lipid nanoparticles containing them at concentrations of 600 and 1200600 
$\mu \mathrm{g} / \mathrm{mL}$ reduced cell viability to $\sim 10 \%$. The prepared nanoformulations could thus be considered for further investigation on other cell lines and in-vivo studies.

\section{Funding}

Fasa University of Medical Sciences has supported this study (Grant Number 99126). Furthermore, this research has also been ethically approved with the ID of IR.FUMS.REC. 1399.139.

\section{Acknowledgments}

Not applicable.

\section{Conflicts of Interest}

There is no conflict of interest amongst the authors.

\section{References}

1. Radecka, B.; Litwiniuk, M. Breast cancer in young women. Ginekol Pol 2016, 87, 659-663, https://doi.org/10.5603/gp.2016.0062.

2. Pavri, S.N.; Clune, J.; Ariyan, S.; Narayan, D. Malignant Melanoma: Beyond the Basics. Plast Reconstr Surg 2016, 138, 330e-340e, https://doi.org/10.1097/prs.0000000000002367.

3. Ossio, R.; Roldan-Marin, R.; Martinez-Said, H.; Adams, D.J.; Robles-Espinoza, C.D. Melanoma: a global perspective. Nature Reviews Cancer 2017, 17, 393-394, https://doi.org/10.1038/nrc.2017.43.

4. Rozzo, C.; Sanna, D.; Garribba, E.; Serra, M.; Cantara, A.; Palmieri, G.; Pisano, M. Antitumoral effect of vanadium compounds in malignant melanoma cell lines. Journal of inorganic biochemistry 2017, 174, 1424, https://doi.org/10.1016/j.jinorgbio.2017.05.010.

5. Massi, D.; Brusa, D.; Merelli, B.; Ciano, M.; Audrito, V.; Serra, S.; Buonincontri, R.; Baroni, G.; Nassini, R.; Minocci, D. PD-L1 marks a subset of melanomas with a shorter overall survival and distinct genetic and morphological characteristics. Ann. Oncol. 2014, 25, 2433-2442, https://doi.org/10.1093/annonc/mdu452.

6. Maksimović-Ivanić, D.; Bulatović, M.; Edeler, D.; Bensing, C.; Golić, I.; Korać, A.; Kaluđerović, G.N. The interaction between SBA-15 derivative loaded with $\mathrm{Ph}(3) \mathrm{Sn}(\mathrm{CH}(2))(6) \mathrm{OH}$ and human melanoma A375 cell line: uptake and stem phenotype loss. J Biol Inorg Chem 2019, 24, 223-234, https://doi.org/10.1007/s00775019-01640-x.

7. Abd El-Aziz, A.R.M.; Al-Othman, M.R.; Mahmoud, M.A.; Shehata, S.M.; Abdelazim, N.S. Chitosan nanoparticles as a carrier for Mentha longifolia extract: synthesis, characterization and antifungal activity. Curr. Sci 2018, 114, 2116-2122, https://doi.org/10.18520/cs/v114/i10/2116-2122.

8. Breast Cancer Statistics. Available online: https://www.cdc.gov/cancer/breast/statistics/index.htm (accessed on January 2021)

9. Comşa, Ş.; Cimpean, A.M.; Raica, M. The story of MCF-7 breast cancer cell line: 40 years of experience in research. Anticancer. Res. 2015, 35, 3147-3154.

10. Jänicke, R.U. MCF-7 breast carcinoma cells do not express caspase-3. Breast Cancer Res. Treat. 2009, 117, 219-221, https://doi.org/10.1007/s10549-008-0217-9.

11. Wang, W.L.; Porter, W.; Burghardt, R.; Safe, S.H. Mechanism of inhibition of MDA-MB-468 breast cancer cell growth by 2, 3, 7, 8-tetrachlorodibenzo-p-dioxin. Carcinogenesis 1997, 18, 925-933, https://doi.org/10.1093/carcin/18.5.925.

12. Androutsopoulos, V.; Arroo, R.R.; Hall, J.F.; Surichan, S.; Potter, G.A. Antiproliferative and cytostatic effects of the natural product eupatorin on MDA-MB-468 human breast cancer cells due to CYP1-mediated metabolism. Breast Cancer Res. 2008, 10, R39, https://doi.org/10.1186/bcr2090.

13. Osanloo, M.; Ghaznavi, G.; Abdollahi, A. Surveying the chemical composition and antibacterial activity of essential oils from selected medicinal plants against human pathogens. Iranian Journal of Microbiology 2020, 12, 577-583, https://doi.org/10.18502/ijm.v12i6.5032.

14. Elmastas, M.; Celik, S.M.; Genc, N.; Aksit, H.; Erenler, R.; Gulcin, İ. Antioxidant activity of an Anatolian herbal tea-Origanum minutiflorum: isolation and characterization of its secondary metabolites. International journal of food properties 2018, 21, 374-384, https://doi.org/10.1080/10942912.2017.1416399.

15. Villaverde, J.J.; Sandín-España, P.; Sevilla-Morán, B.; López-Goti, C.; Alonso-Prados, J.L. Biopesticides from natural products: Current development, legislative framework, and future trends. BioResources 2016, 11, 5618-5640, https://doi.org/10.15376/biores.11.2.villaverde. 
16. Gulcin, I.; Kaya, R.; Goren, A.C.; Akincioglu, H.; Topal, M.; Bingol, Z.; Cetin Çakmak, K.; Ozturk Sarikaya, S.B.; Durmaz, L.; Alwasel, S. Anticholinergic, antidiabetic and antioxidant activities of cinnamon (Cinnamomum verum) bark extracts: polyphenol contents analysis by LC-MS/MS. International Journal of Food Properties 2019, 22, 1511-1526, https://doi.org/10.1080/10942912.2019.1656232.

17. Bai, X.; Aimila, A.; Aidarhan, N.; Duan, X.; Maiwulanjiang, M. Chemical constituents and biological activities of essential oil from Mentha longifolia: effects of different extraction methods. International Journal of Food Properties 2020, 23, 1951-1960, https://doi.org/10.1080/10942912.2020.1833035.

18. Jafari-Sales, A.; Hossein-Nezhad, P.; Bolouri, P. Identification of chemical composition of essential oil and evaluation of antimicrobial effects of ethanolic extract of Mentha pulegium on Staphylococcus aureus and Escherichia coli. Health Biotechnology and Biopharma 2019, 3, 29-38, http://dx.doi.org/10.22034/HBB.2019.10.

19. Brahmi, F.; Khodir, M.; Mohamed, C.; Pierre, D. Chemical composition and biological activities of Mentha species. Aromatic and medicinal plants-Back to nature 2017, 47-78, https://doi.org/10.5772/67291.

20. Mikaili, P.; Mojaverrostami, S.; Moloudizargari, M.; Aghajanshakeri, S. Pharmacological and therapeutic effects of Mentha Longifolia L. and its main constituent, menthol. Ancient science of life 2013, 33, 131, https://doi.org/10.4103/0257-7941.139059.

21. Hadi, M.Y.; Hameed, I.H.; Ibraheam, I.A. Mentha pulegium: Medicinal uses, Anti-Hepatic, Antibacterial, Antioxidant effect and Analysis of Bioactive Natural Compounds: A Review. Research Journal of Pharmacy and Technology 2017, 10, 3580-3584, https://doi.org/10.5958/0974-360x.2017.00648.5.

22. Mahboubi, M.; Haghi, G. Antimicrobial activity and chemical composition of Mentha pulegium L. essential oil. Journal of ethnopharmacology 2008, 119, 325-327, https://doi.org/10.1016/j.jep.2008.07.023.

23. Yassin, M.T.; Mostafa, A.A.; Al-Askar, A.A. Anticandidal and anti-carcinogenic activities of Mentha longifolia (Wild Mint) extracts in vitro. Journal of King Saud University-Science 2020, 32, 2046-2052, https://doi.org/10.1016/j.jksus.2020.02.008.

24. Zouari-Bouassida, K.; Trigui, M.; Makni, S.; Jlaiel, L.; Tounsi, S. Seasonal variation in essential oils composition and the biological and pharmaceutical protective effects of Mentha longifolia leaves grown in Tunisia. BioMed research international 2018, 2018, https://doi.org/10.1155/2018/7856517.

25. Khushnud, T.; Mousa, S.A. Potential role of naturally derived polyphenols and their nanotechnology delivery in cancer. Molecular biotechnology 2013, 55, 78-86, https://doi.org/10.1007/s12033-012-9623-7.

26. Bisht, S.; Feldmann, G.; Soni, S.; Ravi, R.; Karikar, C.; Maitra, A.; Maitra, A. Polymeric nanoparticleencapsulated curcumin ("nanocurcumin"): a novel strategy for human cancer therapy. Journal of nanobiotechnology 2007, 5, 3, https://doi.org/10.1186/1477-3155-5-3.

27. Scheffel, U.; Rhodes, B.A.; Natarajan, T.K.; Wagner, H.N., Jr. Albumin microspheres for study of the reticuloendothelial system. J Nucl Med 1972, 13, 498-503.

28. Mukherjee, S.; Ray, S.; Thakur, R.S. Solid lipid nanoparticles: a modern formulation approach in drug delivery system. Indian J Pharm Sci 2009, 71, 349-358, https://doi.org/10.4103/0250-474x.57282.

29. Moemenbellah-Fard, M.D.; Abdollahi, A.; Ghanbariasad, A.; Osanloo, M. Antibacterial and leishmanicidal activities of Syzygium aromaticum essential oil versus its major ingredient, eugenol. Flavour and Fragrance Journal 2020, 35, 534-540, https://doi.org/10.1002/ffj.3595.

30. Danaei, M.; Dehghankhold, M.; Ataei, S.; Hasanzadeh Davarani, F.; Javanmard, R.; Dokhani, A.; Khorasani, S.; Mozafari, M.R. Impact of Particle Size and Polydispersity Index on the Clinical Applications of Lipidic Nanocarrier Systems. Pharmaceutics 2018, 10, https://doi.org/10.3390/pharmaceutics10020057.

31. Fan, W.; Yu, Z.; Peng, H.; He, H.; Lu, Y.; Qi, J.; Dong, X.; Zhao, W.; Wu, W. Effect of particle size on the pharmacokinetics and biodistribution of parenteral nanoemulsions. International Journal of Pharmaceutics 2020, 586, 119551, https://doi.org/10.1016/j.ijpharm.2020.119551.

32. Mostafa, D.A.; Bayoumi, F.S.; Taher, H.M.; Abdelmonem, B.H.; Eissa, T.F. Antimicrobial potential of Mentha Spp. essential oils as raw and loaded solid lipid nanoparticles against dental caries. Research Journal of Pharmacy and Technology 2020, 13, 4415-4422, https://doi.org/10.5958/0974-360X.2020.00781.7.

33. Kelidari, H.R.; Moemenbellah-Fard, M.D.; Morteza-Semnani, K.; Amoozegar, F.; Shahriari-Namadi, M.; Saeedi, M.; Osanloo, M. Solid-lipid nanoparticles (SLN) s containing Zataria multiflora essential oil with nocytotoxicity and potent repellent activity against Anopheles stephensi. Journal of Parasitic Diseases 2021, 45, 101-108, https://doi.org/10.1007/s12639-020-01281-x.

34. Nasseri, M.; Golmohammadzadeh, S.; Arouiee, H.; Jaafari, M.R.; Neamati, H. Antifungal activity of Zataria multiflora essential oil-loaded solid lipid nanoparticles in-vitro condition. Iranian journal of basic medical sciences 2016, 19, 1231, https://doi.org/10.22038/IJBMS.2016.7824.

35. Zhao, Y.; Chang, Y.-X.; Hu, X.; Liu, C.-Y.; Quan, L.-H.; Liao, Y.-H. Solid lipid nanoparticles for sustained pulmonary delivery of Yuxingcao essential oil: Preparation, characterization and in vivo evaluation. International journal of pharmaceutics 2017, 516, 364-371, https://doi.org/10.1016/j.ijpharm.2016.11.046.

36. Makled, S.; Boraie, N.; Nafee, N. Nanoparticle-mediated macrophage targeting - a new inhalation therapy tackling tuberculosis. Drug Delivery and Translational Research 2020, 1-19, https://doi.org/10.1007/s13346020-00815-3.

37. Hajizadeh, M.R.; Maleki, H.; Barani, M.; Fahmidehkar, M.A.; Mahmoodi, M.; Torkzadeh-Mahani, M. In vitro cytotoxicity assay of D-limonene niosomes: an efficient nano-carrier for enhancing solubility of plant- 
extracted agents. Research in pharmaceutical sciences 2019, 14, 448, https://doi.org/10.4103/17355362.268206 .

38. Osanloo, M.; Arish, J.; Sereshti, H. Developed methods for the preparation of electrospun nanofibers containing plant-derived oil or essential oil: a systematic review. Polymer Bulletin 2020, 77, 6085-6104, https://doi.org/10.1007/s00289-019-03042-0.

39. Yousefian Rad, E.; Homayouni Tabrizi, M.; Ardalan, P.; Seyedi, S.M.R.; Yadamani, S.; Zamani-Esmati, P.; Haghani Sereshkeh, N. Citrus lemon essential oil nanoemulsion (CLEO-NE), a safe cell-depended apoptosis inducer in human A549 lung cancer cells with anti-angiogenic activity. Journal of microencapsulation 2020, 37, 394-402, https://doi.org/10.1080/02652048.2020.1767223.

40. Zielińska, A.; Martins-Gomes, C.; Ferreira, N.R.; Silva, A.M.; Nowak, I.; Souto, E.B. Anti-inflammatory and anticancer activity of citral: Optimization of citral-loaded solid lipid nanoparticles (SLN) using experimental factorial design and LUMiSizer®. Int $J$ Pharm 2018, 553, 428-440, https://doi.org/10.1016/j.ijpharm.2018.10.065.

41. Tang, L.; Yang, X.; Yin, Q.; Cai, K.; Wang, H.; Chaudhury, I.; Yao, C.; Zhou, Q.; Kwon, M.; Hartman, J.A.; Dobrucki, I.T.; Dobrucki, L.W.; Borst, L.B.; Lezmi, S.; Helferich, W.G.; Ferguson, A.L.; Fan, T.M.; Cheng, J. Investigating the optimal size of anticancer nanomedicine. Proceedings of the National Academy of Sciences 2014, 111, 15344, https://doi.org/10.1073/pnas.1411499111.

42. Bao, H.; Zhang, Q.; Xu, H.; Yan, Z. Effects of nanoparticle size on antitumor activity of 10hydroxycamptothecin-conjugated gold nanoparticles: in vitro and in vivo studies. Int J Nanomedicine 2016, 11, 929-940, https://doi.org/10.2147/ijn.s96422.

43. Abedinpour, N.; Ghanbariasad, A.; Taghinezhad, A.; Osanloo, M. Preparation of Nanoemulsions of Mentha piperita Essential Oil and Investigation of Their Cytotoxic Effect on Human Breast Cancer Lines. BioNanoScience 2021, https://doi.org/10.1007/s12668-021-00827-4.

44. Souto, E.B.; Zielinska, A.; Souto, S.B.; Durazzo, A.; Lucarini, M.; Santini, A.; Silva, A.M.; Atanasov, A.G.; Marques, C.; Andrade, L.N. (+)-Limonene 1, 2-epoxide-loaded slns: Evaluation of drug release, antioxidant activity, and cytotoxicity in an HaCaT cell line. International Journal of Molecular Sciences 2020, 21, 1449, https://doi.org/10.3390/ijms21041449.

45. Li, P.-H.; Lu, W.-C. Effects of storage conditions on the physical stability of d-limonene nanoemulsion. Food Hydrocolloids 2016, 53, 218-224, https://doi.org/10.1016/j.foodhyd.2015.01.031. 